\title{
Effects of mechanical conditions on tearing characteristics of zipper band made of white-clay-coated paperboard (Dependency of tearing characteristics on length of connecting portions, width of band and pulling direction)
}

\author{
Shigeru NAGASAWA*, Masahiro UEHARA* and Chiharu MATSUMOTO** \\ *Department of Mechanical Engineering, Nagaoka University of Technology \\ 1603-1 Kamitomioka, Nagaoka-shi, Niigata 940-2188, Japan \\ E-mail: snaga@mech.nagaokaut.ac.jp \\ ${ }^{* *}$ Product Development Group, Taiyo Package Corp. \\ 183-1 Rita, Tateyama-machi, Toyama 930-0275, Japan
}

Received: 12 October 2020; Revised: 29 December 2020; Accepted: 1 February 2021

\begin{abstract}
Packaging boxes are often sealed by a paperboard based flap and also processed so as to have a zipper band (pull tab) structure near the flap. The zipper band structure is used for opening the flap by tearing zipper dash lines which are cut off by using a repeatedly nicked (perforation formed) wedge blade. There are empirically various design patterns of zipper band. In order to arrange the geometrical design parameters of zipper band, the tearing characteristics of zipper-connecting portions must be clarified. In this work, in order to reveal the tearing strength and the success rate of connecting portions (uncut zones), a length of connecting portions and a width of zipper band were widely changed and the pulling direction (attitude) of clamped end of zipper band was also changed. The relationship between the tearing strength and the across direction of cutting line to the grainy direction of paperboard was investigated. Through the experiment, it was found that in-plane de-lamination and tore protrusion occurred at the connecting portions in the band area. Since this de-lamination seemed to be related to the fault of peeling, the effects of pulling attitude (angle) of clamped end of zipper band on the success rate was discussed. As for the upper critical length of connecting portions, at which the success rate became zero, the upper bound tearing strength was gotten and related to the Elmendorf value.
\end{abstract}

Keywords : Zipper pull tab, Nick, Peeling, Delamination, Tearing strength, Grainy, Fiberboard

\section{Introduction}

Coated-recycled paperboard is considered to be a fundamental material for the packaging industry due to its advantages such as high strength-to-weight ratio, high surface smoothness, printability, sustainability, recyclability, and so on. To convert paperboard into a packaging container, a raw paperboard is first printed at a printing line. Then, it is subjected to cutting and creasing processes (Kirwan, 2013). The stripped blank is folded and glued to obtain a packaging carton, the structure of which is designed in several styles (Kirwan, 2013). For examples, there are a seal end, tuck top auto bottom, tuck end, sleeve, lock corner tray, walker lock tray (All packaging company, 2016). Since a closed packaging box is considered to be easily or smoothly opened by customers, a sort of tearing band (zipper pull tab), which is formed in the die-cutting process, is often designed and implemented on the packaging box flap. The zipper band for opening a box flap normally consists of two parallel dashed lines, which are perforation for tearing. Although such a zipper band is widely used for opening a sealed carton, there seemed to be not any standardized cutting patterns of zipper band yet. There are empirically various cutting patterns of zipper band for each manufacturer. However, there are not any public designing methods and theoretical discussion on mechanics of tearing characteristics of zipper band.

Regarding the failure behavior of paper, the mode III tear test as the Elmendorf test is known and standardized 
(Bronkhorst et al., 1983; Lyne et al., 1972). In this tearing, the fracture surface appears to be mixed-mode of inclined breaking across to the out-of-plane. Since this test method seems to evaluate the tear strength of plain thin paper or paperboard without any cutting line, a certain finite length of nick zone should be analyzed for knowing its fracture behavior. According to Yamauchi et al. (2002), an Elmendor tear index was statistically equal to a tear index of tensile testing of the specified papers, the thickness of which was $0.055,0.022$ and $0.174 \mathrm{~mm}$. Namely, an out-of-plane tearing of paper by using an uni-axial tensile testing method shows a similar tearing resistance as the Elmendor testing. The outof-plane shear breaking behavior of white-coated paperboard, the thickness of which was $0.47 \mathrm{~mm}$, was experimentally investigated and the out-of-plane shear strength was reported as the twice or triple times larger as that of in-plane tensile strength (Nagasawa et al., 2010). Also, an in-plane tensile test of a small connecting portion of a $0.47 \mathrm{~mm}$ thickness paperboard was reported by Nagasawa et al. (2008). The in-plane tensile strength of connecting portion was experimentally estimated as the same as that of plain specimen when the length of connecting portion was larger than the thickness of paperboard, although the crushed tip thickness of cutting blade affected (made weak) the tensile strength of connecting portion. The three dimensional deformation of cutting line-end during wedge cutting of paperboard (Nagasawa et al., 2007) and rubber fixtures effects on the wedge cutting characteristics of paperboard were related to the tearing performance of zipper band (Nagasawa et al., 2009). However, those press machine conditions, such as the rubber fixture effect and blade tip crushing, are the secondary factors for characterizing the tearing deformation of band. The primary factors seem to be a width of band, a length of connecting portion (or length of cutting off line), a pattern of inducing route and other geometric patterns of perforation (e.g., dual-close dashed-cutting lines).

The authors experimentally investigated the tearing tensile force and breaking modes of the connecting portions, while varying some representative parameters such as the pitch of nicks and the profile of the entry guide parts (Nagasawa et al., 2018). As the results, it was reported that appropriate guiding routes embedded in the band zone contributed to cut off connecting portions when the perforation of band was across the grain direction of $310 \mathrm{~g} / \mathrm{m}^{2}$ paperboard. The success rate of separation of connecting portions was statistically analyzed with respect to patterns of the specified guiding route, and the inhibition of in-plane de-lamination of zipper band by using the entry guiding route was often necessary to successfully cut off connecting portions. Regarding tearing modes of connecting portion, the stability of tearing as the success rate was discussed with a length of connecting portion in a narrow range, but it was not sufficient to reveal the maximum (upper-bound) tearing force and its corresponded length of connecting portion. As for the stress concentration at the front end of cutting line on the band, a few patterns of entry guiding route (a plain without guide, an inside-inclined guide, and a Y-branched guide) were numerically analyzed using an orthotropic elastic based solid shell FEM model, and the stress intensity was most severe in a vicinity of the front end of cutting line on the lower surface of zipper band (Nagasawa et al., 2017). In this work, in order to reveal the effects of the primary factors (the length and width of connecting portions, and the peeling attitude as a pulling direction) on the breaking modes and the success rate of tearing, a tearing test of zipper band, which was made by plain perforations without any entry guiding route, was experimentally investigated, when choosing the attitude angle of cutting lines against the paper making grain direction as $\phi=0,90^{\circ}$.

\section{Experimental condition and method}

A white-coated paperboard is composed of a pulp fiber structure matrix and a clay coated layer. The fiber layer consists of multiple plies, while the coated layer is a mixture of ground calcium carbonate, kaolin and binder (Reinhard et al., 2013). In this work, a commercially recycled white-coated paperboard which had a thickness $t=0.38 \mathrm{~mm}$ and a nominal basis weight of $310 \mathrm{~g} / \mathrm{m}^{2}$ was chosen. Its fiber and pulp analysis were summarized in Table 1 , while the in-plane tensile properties of the paperboard in the making machine direction (MD) and in the cross machine direction (CD) were shown in Table 2. The anisotropy of mechanical properties with MD and CD affect the tearing behavior of paperboard. Thickness of the coated layer was approximately $20 \mu \mathrm{m}$ which included a thin impregnated paper layer. The rest paper layers were composed of laminated multiple plies (approximately $50 \mu \mathrm{m}$ for each ply).

Figure 1 shows a schematic of zipper specimen for tearing test. Keeping a right side width of flap part $b_{\mathrm{R}}$ equal to a left side width of flap part $b_{\mathrm{L}}$, a width of band part $b$ was chosen as 3,10, $30 \mathrm{~mm}$. A length of connecting portion (uncut part) $a_{\mathrm{n}}$ was basically chosen as $3 \mathrm{~mm}$, when changing the width of band part $b$. The two dashed-cutting lines were processed by using a cemented carbide blade (NSK, N13SB) which had an angular aperture of $30^{\circ}$, a crossing angle of $18.8^{\circ}$. The attitude of dashed-cutting lines was made in across $\left(\phi=90^{\circ}\right)$ and/or in parallel $\left(\phi=0^{\circ}\right)$ to the grain direction (machine direction). 
Table 1 Size of fiber and pulp combination ratio of white-coated paperboard 310 (measured by Kajaani-FS300) L-BKP: Broadleaved lumber (hard wood), bleaching kraft pulp; N-BKP: Needle-leaved lumber (soft wood), bleaching kraft pulp; NTMP: Needle-leaved, thermal mechanical pulp; L(n): based on number of fibers in each fibrillation index class; L(l): based on length weighted number of fibers in each fibrillation index class; $\mathrm{L}(\mathrm{w})$ : based on weight-weighted number of fibers in each fibrillation index class; CWT: Wall thickness of cell; Width: average width of fiber.

\begin{tabular}{l|l|l|l|l|l|l|l|l|l}
\hline \hline Unit & \multicolumn{2}{|l|}{ Pulp combination ratio (\%) } & \multicolumn{4}{l|}{ Projected length of fiber $(\mathrm{mm})$} & \multicolumn{2}{l|}{ Size $(\mu \mathrm{m})$} & Section $\operatorname{area}^{\left(\mu \mathrm{m}^{2}\right)}$ \\
\hline Item & L-BKP & N-BKP & N-TMP & L(n) & L(l) & L(w) & Width & CWT & CSA \\
\hline Value & 44.1 & 23.0 & 32.9 & 0.50 & 0.91 & 1.47 & 18.8 & 5.0 & 259.9 \\
\hline
\end{tabular}

Table 2 In-plane tensile properties of white-coated paperboard in the making machine direction (MD), and the cross machine direction (CD). The average (standard deviation) of ten samples was shown, when choosing the strain rate of $0.00185 \mathrm{~s}^{-1}$ $(V=0.33 \mathrm{~mm} / \mathrm{s}$ ) for elongation. The tensile procedure was based on JIS-P8113.

\begin{tabular}{|c|c|c|c|}
\hline & $\begin{array}{c}\text { Young's modulus } \\
E(\mathrm{GPa})\end{array}$ & $\begin{array}{c}\text { Tensile strength } \\
\sigma_{B}(\mathrm{MPa})\end{array}$ & $\begin{array}{c}\text { Breaking strain } \\
\varepsilon_{B}(\%)\end{array}$ \\
\hline MD & $5.26(0.09)$ & $39.3(1.3)$ & $2.0(0.1)$ \\
\hline $\mathrm{CD}$ & $2.24(0.03)$ & $18.4(0.2)$ & $4.8(0.2)$ \\
\hline
\end{tabular}

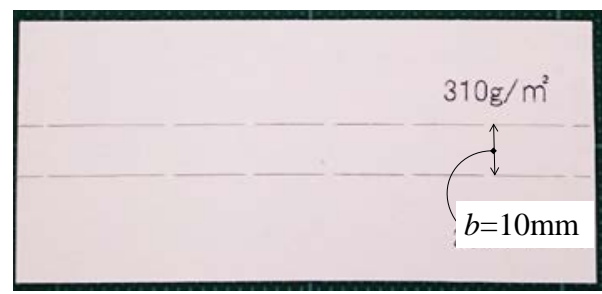

(a) Example of specimen ( $\left.a_{\mathrm{n}}=2 \mathrm{~mm}, b=10 \mathrm{~mm}\right)$

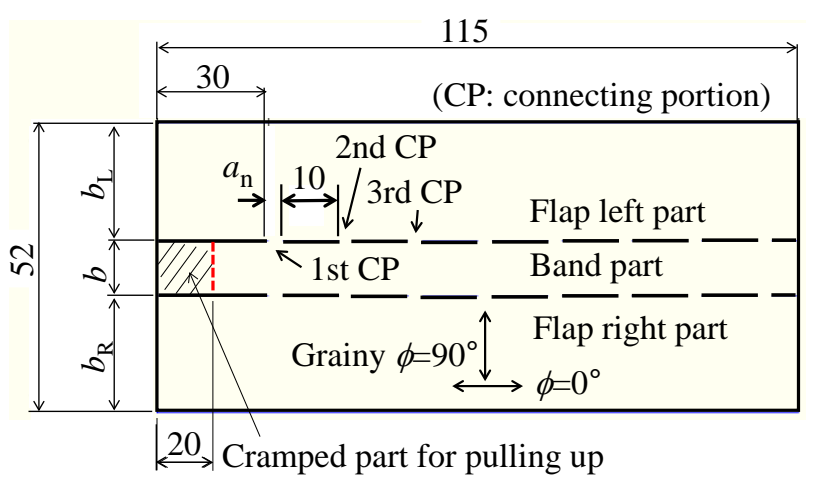

(b) Layout and basic size of specimen

Fig.1 Top view and basic size of specimen for tearing test.

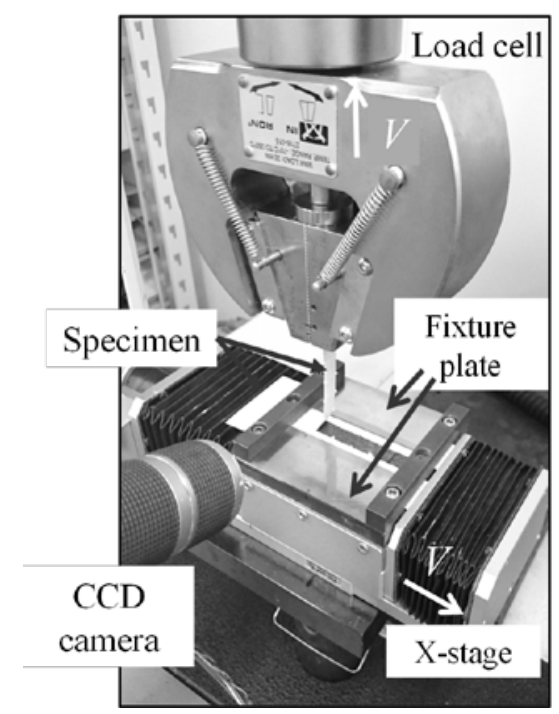

Fig.2 A general view of zipper tearing test apparatus (Ref. Nagasawa et al., 2018).

The hatched area was initially folded at a length of $20 \mathrm{~mm}$ and clamped with a margin of $5 \mathrm{~mm}$ by a pulling fixture device, while the first connecting portion was located at a distance of $10 \mathrm{~mm}$ from this folded position. A length of cutting line between connecting portions (having an uncut part of $a_{\mathrm{n}}$ ) was chosen as $10 \mathrm{~mm}$.

Figure 2 shows a general view of zipper tearing test apparatus (Nagasawa et al., 2018). The apparatus was composed of a tensile testing apparatus with a velocity of $V=16.7 \mathrm{~mm} / \mathrm{s}$ and a X-stage (one dimensional moving table) with a velocity of $V=16.7 \mathrm{~mm} / \mathrm{s}$, when the X-stage was set up horizontally. A white-coated side of specimen was set as the upper side against the X-stage (moving table). Using this pulling motion, the clamped end of band was moved up in the vertical direction. When a specimen was fastened on a horizontal bed by using a window-opened steel plate (fixture plate), the pulling direction of clamped end became $\theta_{a}=90^{\circ}$. Here, since the width of window was $b+2 \times 5 \mathrm{~mm}$, the width of window was chosen as $20 \mathrm{~mm}$ when $b=10 \mathrm{~mm}$. The full stroke of the clamped end was chosen as $45 \mathrm{~mm}$ due to geometrical restriction of the horizontal moving table. Hence, three sets of (first, second and third) connecting portions were torn in a tearing test, and the tensile force of clamped end of band $F$ and the vertical displacement of the clamped end $x$ mm 
were measured. From the three stages of tearing at connecting portions, the first, second, and third peak maximum of tensile force $F_{\mathrm{p} 1}, F_{\mathrm{p} 2}$, and $F_{\mathrm{p} 3}$ were arranged. All specimens were kept for 4 hours in a room which had a temperature of $296 \mathrm{~K}$ and a humidity of $50 \% \mathrm{RH}$. As for the effect of length of connecting portions on the success rate of tearing of connecting portions, the length of connecting portions was chosen as $a_{\mathrm{n}}=1.5,2.0,2.5,3.0,3.5,4.0,4.5,5.0 \mathrm{~mm}$, when keeping the width of band $b=10 \mathrm{~mm}$ and the pulling direction was chosen as $\theta_{a}=90^{\circ}$. Measurements were carried out 10 times for $a_{\mathrm{n}} \leq 2.5 \mathrm{~mm}$, while they were 5 times for $a_{\mathrm{n}} \geq 3.0 \mathrm{~mm}$. Figure 3 shows pulling directions of clamped end of band when choosing (a) $\theta_{a}=120$ and (b) $\theta_{a}=60^{\circ}$. Here, since the specimen was set up at an incline of $30^{\circ}$, the velocity of X-stage was chosen as $16.7 \cos 30^{\circ}=14.5 \mathrm{~mm} / \mathrm{s}$, while the vertical velocity of chuck was $16.7 \mathrm{~mm} / \mathrm{s}$. Regarding the effects of the band width $b=3,10,30 \mathrm{~mm}$ and the pulling directions $\theta_{a}=60,90,120^{\circ}$ on the success rate of tearing of connecting portions, measurements were 10 times, respectively, when keeping $a_{\mathrm{n}}=3 \mathrm{~mm}$. This value of $a_{\mathrm{n}}$ was empirically chosen so as to reveal the effects of $b$ and $\theta_{a}$ on the success rate of tearing.

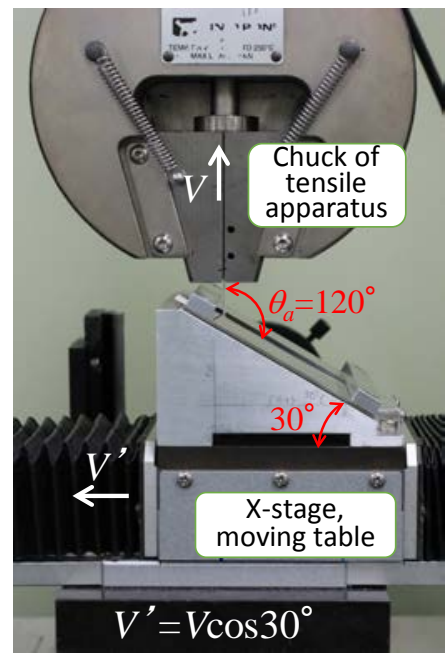

(a) Tearing attitude of $\theta_{a}=120^{\circ}$

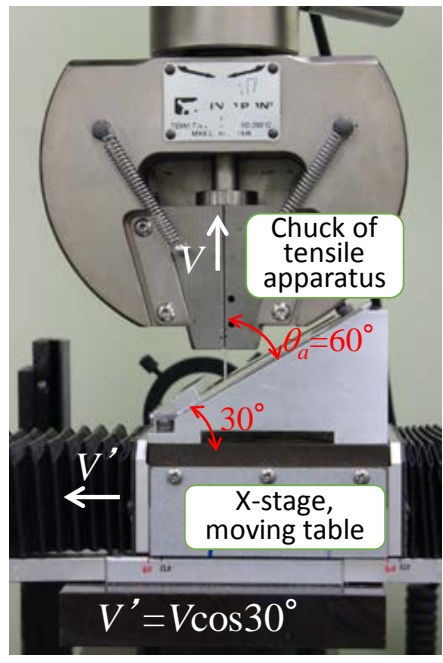

(b) Tearing attitude of $\theta_{a}=60^{\circ}$

Fig.3 General views of zipper tearing apparatus including inclined block.

\section{Experimental results and discussion}

\subsection{Effects of length of connecting portions on tearing off}

The relationship between tensile tearing force and displacement of clamped band end was discussed when $a_{\mathrm{n}}=1.5$, 2.0 and $2.5 \mathrm{~mm}$; and when $b=10 \mathrm{~mm}$ and $\theta_{a}=90^{\circ}$, in case of a plain type without any guiding route as shown in Fig. 1 (Nagasawa et al., 2018).

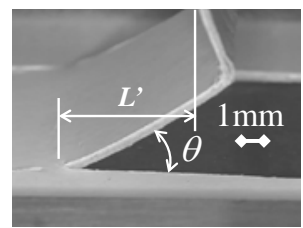

(a) $x \approx 6 \mathrm{~mm}$

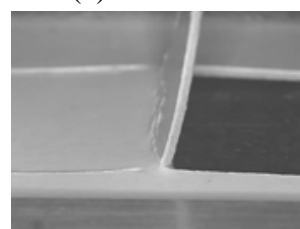

(b) $x \approx 8.5 \mathrm{~mm}$

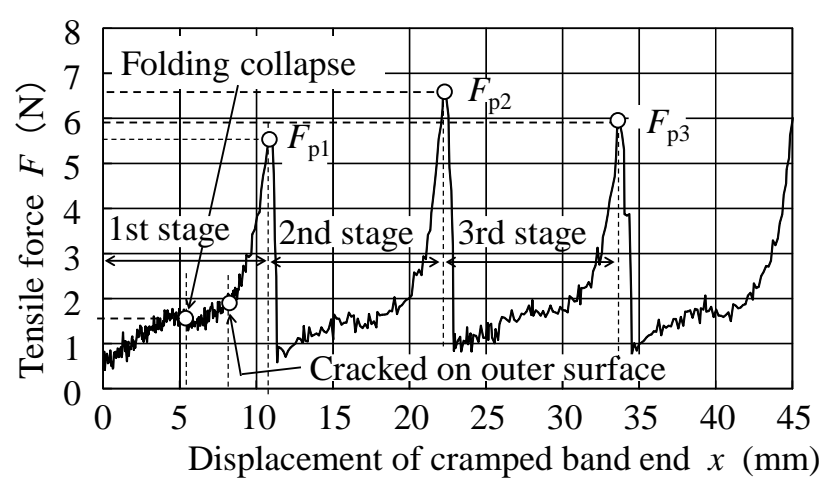

(c) Tearing load response

Fig.4 Folding plastic collapse and crack occurrence in tearing load response of zipper-tearing test for plain type without guiding route when $a_{\mathrm{n}}=1.5 \mathrm{~mm}, \phi=0^{\circ}, \theta_{a}=90^{\circ}$ and $V=16.7 \mathrm{~mm} / \mathrm{s}$ (Ref. Nagasawa et al., 2018).

In this experiment, all the specimens were successfully separated when $\phi=0^{\circ}$ (cutting lines were in parallel to the grain direction of paper making). Figure 4 (a)(b) show photographs of tearing test in the first stage (at positions of $x=6$ 
$\mathrm{mm}$ and $8.5 \mathrm{~mm}$ ) and Fig.4(c) shows representative tearing load response. When the displacement of clamped band end reached $x=6 \mathrm{~mm}$, the bent-up angle of zipper-band was about $\theta=30^{\circ}$ at a projected arm length $L^{\prime}=7.4 \mathrm{~mm}$ and the load response had a gradual peak maximum of $1.5 \mathrm{~N}$. At this state, the upper surface of specimen had a small wrinkles and the bending became permanent. Namely, the gradual peak maximum corresponded to a plastically folding collapse. Seeing Fig. 4 (b) at $x=8.5 \mathrm{~mm}$, cracked area was detected on the outer surface (lower surface). This kind of load response was similarly confirmed at the first stage (until the $F_{\mathrm{p} 1}$ point) when choosing $a_{\mathrm{n}}=1.5 \sim 5.0 \mathrm{~mm}, \theta_{a}=90^{\circ}$ and $\phi=0,90^{\circ}$ in this work.

Figure 5 (a),(b) show photographs of tore profile of connecting portion, when $a_{\mathrm{n}}=2.5 \mathrm{~mm}, \theta_{a}=90^{\circ}$ and $\phi=0$, $90^{\circ}$ (Nagasawa et al., 2018). In this case, torn connecting portions were successfully separated when $\phi=0^{\circ}$, while it failed sometimes when $\phi=90^{\circ}$ due to occurrence of de-lamination in a zipper-band. When continuing a pulling motion of clamped end furthermore, the tearing of connecting portions reached a scene of Fig.5 (c). The failure scene of Fig.5(c) seemed to be generated by propagating de-lamination in an in-plane layer from the burst outer surface of zipper band. From those results, a range of $a_{\mathrm{n}}=2 \sim 2.5 \mathrm{~mm}$ (Nagasawa et al., 2018) seems to be a critical length for successful separation when $\phi=90^{\circ}$, but any critical length of $\phi=0^{\circ}$ is not clarified yet. Therefore, an expanded range of $a_{\mathrm{n}}=1.5 \sim 5.0 \mathrm{~mm}\left(a_{\mathrm{n}} / t=\right.$ 4.0 13.2) was investigated for revealing the critical length of successful separation of connecting portions.

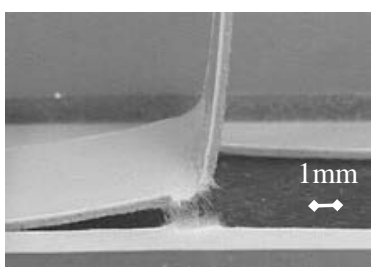

(a) $a_{\mathrm{n}}=2.5 \mathrm{~mm}, \phi=0^{\circ}$

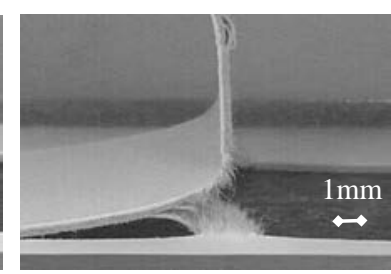

(b) $a_{\mathrm{n}}=2.5 \mathrm{~mm}, \phi=90^{\circ}$

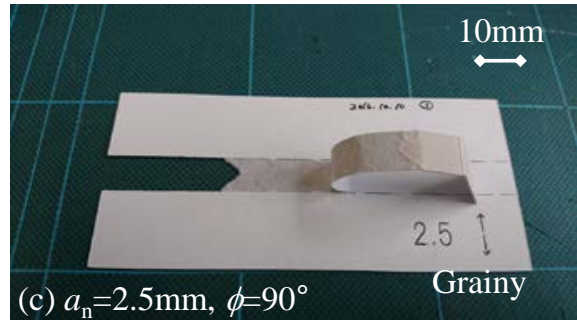

Fig.5 Photographs of tore profile of connecting portions (a), (b) (Ref. Nagasawa et al., 2018) and a failure case (c) after full stroke pulling.

Figure 6 shows two cases of the tearing load response until the third stage (including $F_{\mathrm{p} 1}, F_{\mathrm{p} 2}$ and $F_{\mathrm{p} 3}$ ) when $a_{\mathrm{n}}=5$ $\mathrm{mm}, \phi=0^{\circ}, \theta_{a}=90^{\circ}$. Here, a black load curve was a success of separation of connecting portions for three stages, and a red load curve was a failure at the second stage. The success is counted when three stages are successfully separated. Figure 7 shows the relationship between the success rate of zipper-band separation from flap and the normalized length of connecting portions $a_{\mathrm{n}} / t$ at $\theta_{a}=90^{\circ}$ for $\phi=0,90^{\circ}$. Here, $b=10 \mathrm{~mm}$ was considered. When $a_{\mathrm{n}}>3 \mathrm{~mm}\left(a_{\mathrm{n}} / t>7.9\right)$ in $\phi=0^{\circ}$, remarkable propagation of in-plane delamination of zipper band increased and the separation of connecting portions was failed with a high probability. This was recognized as the lower critical condition to start to decrease the success rate. As for the ultimate unsuccessful separation, the upper critical length of connecting portions seems to be $a_{\mathrm{n}}=5 \sim 6 \mathrm{~mm}\left(a_{\mathrm{n}} / t=\right.$ $13.1 \sim 15.6)$ for $\phi=0^{\circ}$. In case of $\phi=90^{\circ}$, the success rate of separation monotonically decreased from $a_{\mathrm{n}}>1.5 \mathrm{~mm}\left(a_{\mathrm{n}} / t=4\right)$ up to $a_{\mathrm{n}}=3.5 \mathrm{~mm}\left(a_{\mathrm{n}} / t=9.2\right)$. The upper/lower critical lengths of connecting portions for $\phi=90^{\circ}$ were recognized as $a_{\mathrm{n}}=3.5$ $\mathrm{mm}\left(a_{\mathrm{n}} / t=9.2\right)$ and $a_{\mathrm{n}}=1.5\left(a_{\mathrm{n}} / t=3.9\right)$, respectively.

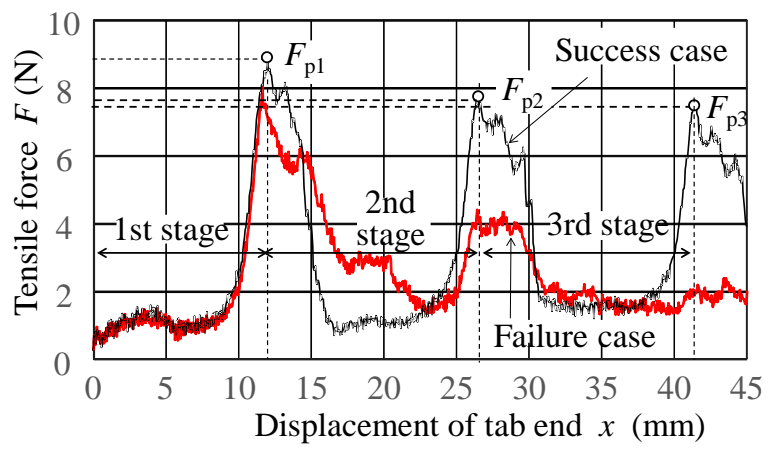

Fig.6 Relationship between tensile line force and displacement of clamped band end when $a_{\mathrm{n}}=5 \mathrm{~mm}, \phi=0^{\circ}$ and $\theta_{a}=90^{\circ}$. 
Figure 8 shows the relationship between the first peak maximum tearing force $F_{\mathrm{p} 1}$ and the normalized length of connecting portions $a_{\mathrm{n}} / t$ at $\theta_{a}=90^{\circ}$ for $\phi=0,90^{\circ}$. Eq.(1) and (2) are approximations of exponentiation rule at $\theta_{a}=90^{\circ}$ for $\phi=0,90^{\circ}$. The normalized length was empirically considered for using the exponentiation rule with a dimensionless parameter. Although the thickness of paperboard was not changed in this work, as the critical length for separation and the burst strength of outside layer seemed to be related to the thickness, the dimensionless $a_{\mathrm{n}} / t$ was arranged here.

$$
\begin{array}{ll}
F_{p 1}=4.19\left(\frac{a_{n}}{t}\right)^{0.2803} & \left(\text { for } \phi=0^{\circ}\right) \\
F_{p 1}=6.81\left(\frac{a_{n}}{t}\right)^{0.0653} & \left(\text { for } \phi=90^{\circ}\right)
\end{array}
$$

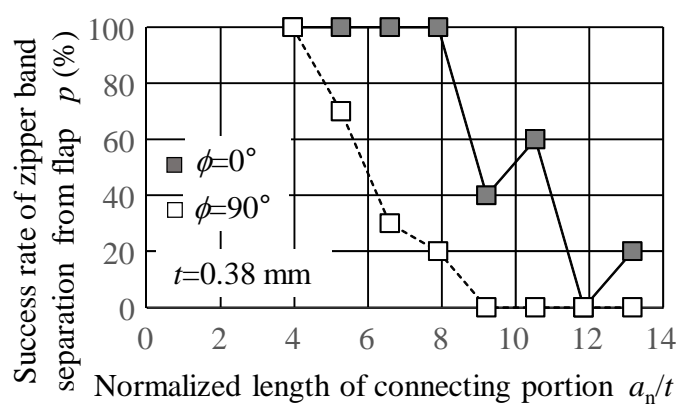

Fig.7 Dependency of success rate on length of connecting portion and grainy direction.

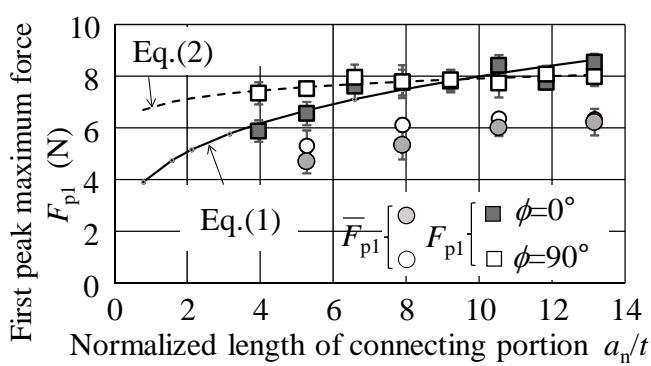

Fig.8 Peak maximum force at the first stage with respect to length of connecting portion.

$$
\bar{F}_{p 1}=\frac{1}{a_{n}} \int_{10}^{10+a_{n}} F d x
$$

As seen in Fig.6 and Fig.4 (c), since the tearing force $F$ remarkably changed with the displacement of clamped band end $x$, an average of the first stage tearing force $\overline{\boldsymbol{F}}_{\boldsymbol{p} \mathbf{1}}$ for a section of $x$ : [10, $\left.10+a_{\mathrm{n}}\right]$ was calculated using Eq.(3) and shown in Fig.8. Here, since the arm length from the hatched-folded position to the end position (bottom) of first cutting line was $10 \mathrm{~mm}, x=10 \mathrm{~mm}$ corresponded that the clamped band was folded in a right angle and pull up in a vertical direction. It was found that $\overline{\boldsymbol{F}}_{\boldsymbol{p} \mathbf{1}}$ was about $6 \mathrm{~N}$ for $a_{\mathrm{n}} / t>10$. This average was empirically calculated so as to avoid a starting section $(x=0 \sim 10 \mathrm{~mm})$ and to consider the duration of a length of connecting portion. Since $\overline{\boldsymbol{F}}_{\boldsymbol{p} \mathbf{1}}$ was evaluated with respect to two cutting lines, its working must be estimated as twice from single tearing work. According to the Elmendorf test at $\phi=90^{\circ}$, its result was $2.53 \mathrm{~N} . \overline{\boldsymbol{F}}_{\boldsymbol{p} \mathbf{1}} \approx 6 \mathrm{~N}$ was a little larger but almost equal to two times of the Elmendorf value. So far, two times of Elmendorf value is useful for estimating an average of tearing force $\overline{\boldsymbol{F}}_{\boldsymbol{p} \mathbf{1}}$ (for $x=10 \sim 10+a_{\mathrm{n}}$ ). The difference of $F_{\mathrm{p} 1}$ from $\overline{\boldsymbol{F}}_{\boldsymbol{p} 1}$ was $2 \sim 3 \mathrm{~N}$ for $a_{\mathrm{n}} / t=5 \sim 13$. The upper bound $F_{\mathrm{p} 1}$ can be estimated as $2 \times$ Elmendorf value (N) $+2 \sim 3 \mathrm{~N}$ in the working condition: $\theta_{a}=90^{\circ}, a_{\mathrm{n}} / t>10$.

\subsection{Effects of width of zipper band on tearing off}

Figure 9 shows examples of tearing test when (a) $b=30 \mathrm{~mm}$ and (b) $b=3 \mathrm{~mm}$, and Fig.10 shows the tearing force response $F$ from the starting position up to the third stage when choosing $b=3,10,30 \mathrm{~mm}$ at $a_{\mathrm{n}}=3 \mathrm{~mm}, \theta_{a}=90^{\circ}$. The tearing separation of connecting portions sometimes failed. Table 3 shows the relationship between the success rate of connecting portions $p \%$ and the width of zipper band $b$ for $\phi=0,90^{\circ}$. It was found that the success rate of separation was higher when $b$ was wider. The tearing success ratio at $\phi=90^{\circ}$ was relatively unstable (low) and the propagation of in-plane delamination was easier than that of $\phi=0^{\circ}$, regardless of the width of band $b$.

Figure 11 shows examples of torn profile of connecting portion in case of $a_{\mathrm{n}}=2.5 \mathrm{~mm}, b=10 \mathrm{~mm}$ and $\theta_{a}=90^{\circ}$. Seeing Fig.11, a height of protrusion of torn zone had the similar length as a length of $a_{\mathrm{n}}$ for $\phi=90^{\circ}$, while that was about a half of $a_{\mathrm{n}}$ for $\phi=0^{\circ}$. A profile of protrusion of torn zone was similar to Fig. 11 when choosing $b=3,10,30 \mathrm{~mm}$ at $a_{\mathrm{n}}=3$ $\mathrm{mm}$. In case of narrow band $b / a_{\mathrm{n}}=1$, in-plane delamination was apt to occur in a full range of the width of zipper band. 


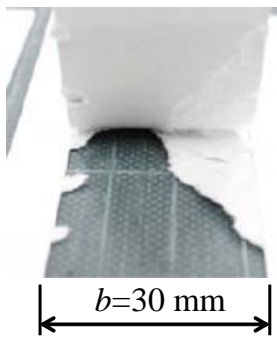

(a)

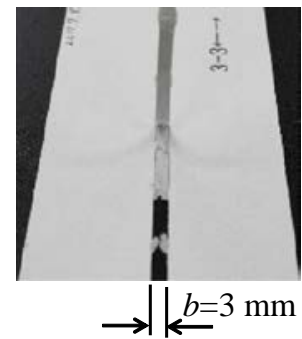

(b)
Table 3 Dependency of success rate on width of zipper band and grainy direction. $a_{\mathrm{n}}=3 \mathrm{~mm}, \theta_{a}=90^{\circ}$.

\begin{tabular}{|c|c|c|c|c|}
\hline $\begin{array}{c}\text { Grain } \\
\text { direction }\end{array}$ & $\begin{array}{l}\text { Width of band } \\
b(\mathrm{~mm})\end{array}$ & 3.0 & 10.0 & 30.0 \\
\hline$\phi=0^{\circ}$ & $\begin{array}{l}\text { Success rate of } \\
\text { tearing } \quad p(\%)\end{array}$ & 0 & 80 & 80 \\
\hline$\phi=90^{\circ}$ & $\begin{array}{l}\text { Success rate of } \\
\text { tearing } p(\%)\end{array}$ & 0 & 10 & 50 \\
\hline
\end{tabular}

Fig.9 Photographs of tearing test at the third stage in case of $a_{\mathrm{n}}=3 \mathrm{~mm}, \phi=90^{\circ}, \theta_{a}=90^{\circ}$.

Furthermore, the bending curvature radius at a position of folding collapse, as shown in Fig.4 (a)(b), is apt to be smaller when $b$ is narrower. Because the out-of-plane bending stiffness of band is varied with $b$, while the tearing peak maximum force $F_{\text {pi }}(\mathrm{i}=1,2,3)$ is basically constant when fixing $a_{\mathrm{n}}$. In this situation (a narrow width), the outside layer of bent band has a high tensile stress state. Such a high tensile stress state induces a burst of the outside layer of band and a propagation of in-plane delamination of band.

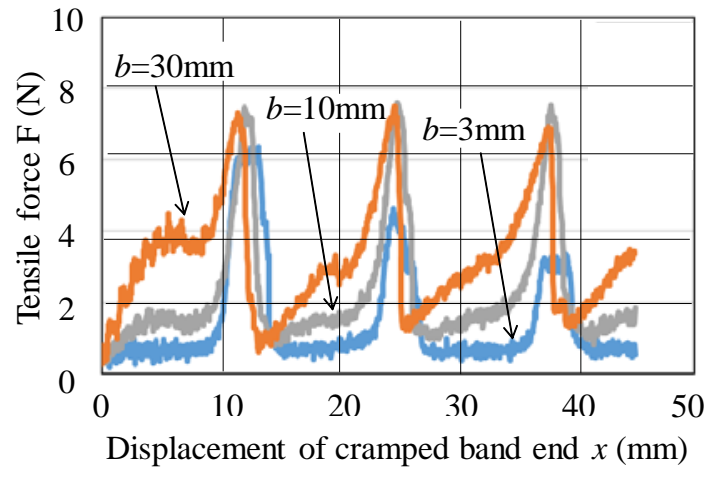

(a) $a_{\mathrm{n}}=3 \mathrm{~mm}, \phi=0^{\circ}$

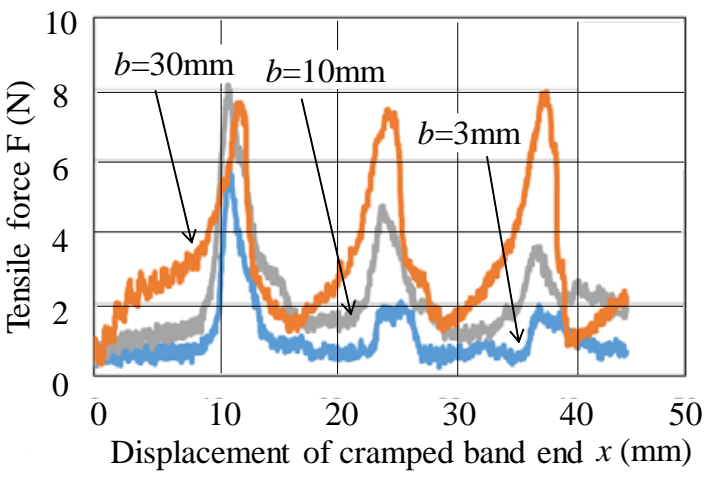

(b) $a_{\mathrm{n}}=3 \mathrm{~mm}, \phi=90^{\circ}$

Fig.10 Relationship between tearing tensile force and displacement of clamped end when varying width of band.

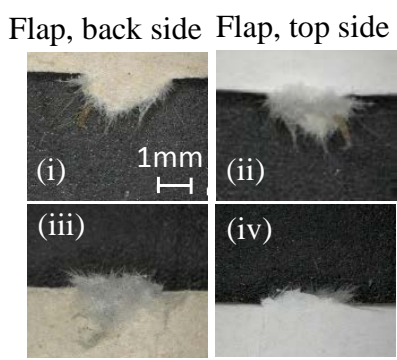

Band, back side Band, top side (a) $\phi=0^{\circ}$
Flap, back side Flap, top side

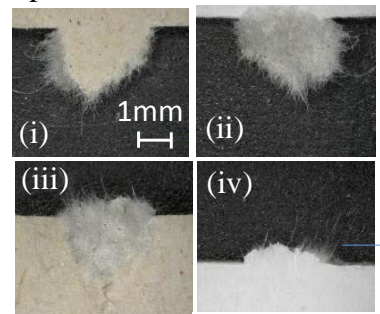

Band, back side Band, top side

(b) $\phi=90^{\circ}$

Fig.11 Top views of successful-torn zone of connecting portion in case of $a_{\mathrm{n}}=2.5 \mathrm{~mm}, b=10 \mathrm{~mm}$.

(i) Back side of flap; (ii) Top side of flap; (iii) Back side of band; and (iv) Top side of band.

To the contrary, when choosing a wide band $b / a_{\mathrm{n}}=10(b=30 \mathrm{~mm})$, since the out-of-plane bending stiffness is relatively large by increasing $b$, the bending tensile stress is restrained at the outside layer and the bending curvature radius increases at the folding position owing that the tearing peak maximum force is basically constant under fixing $a_{\mathrm{n}}$. Furthermore, since a wide band has relatively a large bending deflection in the pulling-up direction, the in-plane tensile stress relatively increases in the lateral (width) direction of zipper band at the tearing zone of connecting portion. So far, it is understood that the out-of-plane shear stress and the in-plane tensile stress contribute to split the connecting portion in stable.

\subsection{Effects of pulling attitude of clamped end on tearing off}

Using additional inclined block shown in Fig.3, the pulling direction of clamped band end was changed as $\theta_{a}=60$, 
90 and $120^{\circ}$ in case of $a_{\mathrm{n}}=3 \mathrm{~mm}, b=10 \mathrm{~mm}$. Figure 12 shows the peak maximum tearing forces $F_{\mathrm{p} 1}, F_{\mathrm{p} 2}$ and $F_{\mathrm{p} 3}$ at the first, second and third stages. The relationship between the tearing success ratio of connecting portions $p \%$ and the pulling direction (angle of attitude) $\theta_{a}$ is shown in Table 4. The tearing success ratio increased with the pulling direction of clamped band end $\theta_{a}$. In case of $\theta_{a}=120^{\circ}$, the tearing force $F_{120}$ is principally distributed into the out-of-plane pullingup force $F_{120} \cos \left(\theta_{a}-90^{\circ}\right)=0.866 F_{120}$ and the in-plane tensile force $F_{120} \sin \left(\theta_{a}-90^{\circ}\right)=0.5 F_{120}$. Seeing Fig.12, a ratio of experimental average force was $F_{\mathrm{p} 1,90} / F_{\mathrm{p} 1,120}=7.67 / 10.3=0.74$ at $\phi=0^{\circ}$ and that was $7.87 / 11.2=0.70$ at $\phi=90^{\circ}$. Although they were a little smaller than 0.866 , the ratio can be estimated from this cosine. Namely, the peak maximum tearing force at $\theta_{a}=120^{\circ}$ contributed to split the connecting portion by using the out-of-plane shear and the in-plane tensile forces.

Table 4 Dependency of success rate on angle of pulling direction and grainy direction. $a_{\mathrm{n}}=3 \mathrm{~mm}, b=10 \mathrm{~mm}$.

\begin{tabular}{|c|c|c|c|c|}
\hline $\begin{array}{l}\text { Grain } \\
\text { direction }\end{array}$ & $\begin{array}{l}\text { Pulling direction } \\
\theta_{a}\left({ }^{\circ}\right)\end{array}$ & 60 & 90 & 120 \\
\hline$\phi=0^{\circ}$ & $\begin{array}{l}\text { Success rate of } \\
\text { tearing } \quad p(\%)\end{array}$ & 60 & 80 & 100 \\
\hline$\phi=90^{\circ}$ & $\begin{array}{l}\text { Success rate of } \\
\text { tearing } \quad p(\%)\end{array}$ & 0 & 10 & 30 \\
\hline
\end{tabular}

Since the latter of in-plane tensile force makes an in-plane shear stress at the nearest connecting portion, the tearing success ratio at the nearest connecting portion seems to increase, compared with that of $\theta_{a}=90^{\circ}$. At the same time, the folding angle of band $\left(60^{\circ}\right)$ is small and the bending curvature radius of band at the nearest connecting portion is expected to be large under the in-plane tensile force of $F_{120} \sin \left(\theta_{a}-90^{\circ}\right)$ when $\theta_{a}=120^{\circ}$, compared to that of $\theta_{a}=90^{\circ}$. Therefore, a tensile strain at the outside layer and any in-plane delamination of band seem to be restrained. Synthetically, the performance of separation at $\theta_{a}=120$ is superior to that of $\theta_{a}=90^{\circ}$.

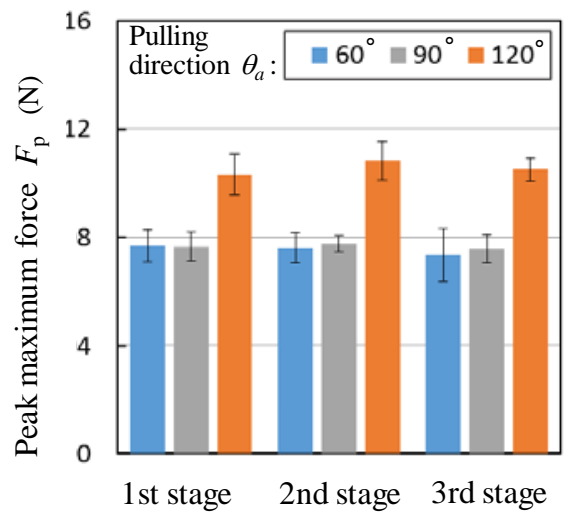

(a) $\phi=0^{\circ}, a_{\mathrm{n}}=3 \mathrm{~mm}, b=10 \mathrm{~mm}$

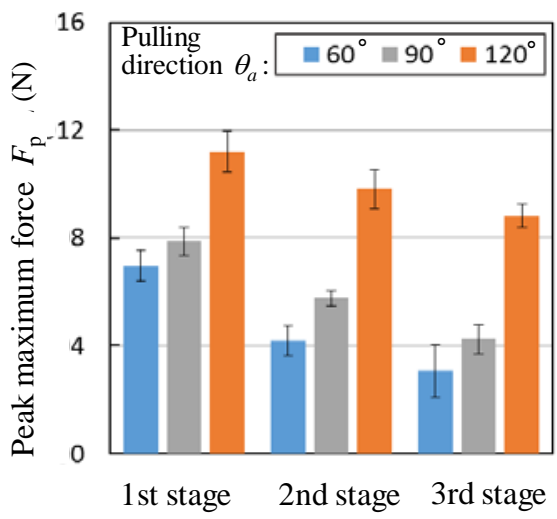

(b) $\phi=90^{\circ}, a_{\mathrm{n}}=3 \mathrm{~mm}, b=10 \mathrm{~mm}$

Fig.12 Comparison of peak maximum force with respect to angle of pulling direction.

On the other hand, when $\theta_{a}=60^{\circ}$, as the folding angle $\left(120^{\circ}\right)$ is larger than that of $\theta_{a}=90^{\circ}$, the tensile strain increases at the outside layer and then the burst of outside layer tends to easily occur. Furthermore, since the out-of-plane bending stiffness increase with the folding angle, the bending deflection of band in the lateral (width) direction is restrained. Then, any in-plane tensile stress by the out-of-plane bending deflection is prohibited. So far, those conditions early induce the in-plane delamination and the tensile burst of outside layer of band. Seeing Fig.12, $F_{\mathrm{p} 1,60}$ was close to $F_{\mathrm{p} 1,90}$ for $\phi=0,90^{\circ}$. This means that the out-of-plane shearing resistance is almost determined by the sectional area, regardless of $\theta_{a}$.

In case of $\phi=90^{\circ}$ for three pulling directions of 60,90 and $120^{\circ}$, the success rate was not so high, as shown in Table 4. This was mainly caused by propagation of in-plane delamination as shown in Fig.5(b). Decrease of $F_{\text {pi }}$ (peak at the ith stage) had a correlation with a failure of separation of connecting portion (decrease of the success rate). 


\section{Conclusions}

A simple zipper band without guiding route was prepared using a $310 \mathrm{~g} / \mathrm{m}^{2}$ white-coated paperboard (the thickness of which was $t=0.38 \mathrm{~mm}$ ) and a tearing test of zipper band was carried out when changing the length of connecting portions $a_{\mathrm{n}}$, the width of zipper band $b$, and the angle of pulling direction (attitude) of clamped end of zipper band $\theta_{a}$. Through the experiment, the followings were revealed.

(1) The relationship between the first peak maximum tearing force $F_{\mathrm{p} 1}$ and the normalized length of connecting portion $a_{\mathrm{n}} / t$ was revealed using experimental approximations based on an exponentiation rule. The upper critical length of $a_{\mathrm{n}} / t$, at which the success rate became zero, was $13.1 \sim 15.6$ for $\phi=0^{\circ}$ (cut in parallel to the grainy), while it was 9.2 for $\phi=90^{\circ}$ (cut across the grainy), in case of $\theta_{a}=90^{\circ}$ and $b=10 \mathrm{~mm}$. The lower critical length of $a_{\mathrm{n}} / t$, at which the success rate started to decrease, was 8 for $\phi=0^{\circ}$, while it was 4 for $\phi=90^{\circ}$.

(2) The upper bound of the first peak maximum tearing force $F_{\mathrm{p} 1}$ was estimated as $2 \times$ Ermendorf value $(\mathrm{N})$ plus $2 \sim 3$ $\mathrm{N}$ for $a_{\mathrm{n}} / t>10$ regardless of cutting direction against the grainy of paper making, in case of $\theta_{a}=90^{\circ}$.

(3) Dependency of the width of zipper band on the success rate was statistically revealed. To increase the width of zipper band contributes to suppress the failure of separation of connecting portions.

(4) The pulling direction (attitude) of clamped end of zipper band affects the success rate. When $\theta_{a}>90^{\circ}\left(120^{\circ}\right.$ was investigated), the success rate of connecting portions $p$ was higher than that of $\theta_{a}=90^{\circ}$. When $\theta_{a}<90^{\circ}\left(60^{\circ}\right.$ was investigated), the success rate $p$ was lower than that of $\theta_{a}=90^{\circ}$. The pulling direction of $\theta_{a}=120^{\circ}$ is superior to that of $\theta_{a}=90$ or $60^{\circ}$ with respect to the success rate, while the peak maximum tearing force is relatively large at $\theta_{a}=120^{\circ}$, compared to that of $\theta_{a}=90$ or $60^{\circ}$.

(5) Using the proposed method, in which the pulling direction of clamped end of zipper band was vertical to a horizontal X-stage, in-plane delamination and tore protrusions occurred at the zipper band area. Tore protrusions were left on the flap side.

This work was carried out using a limited condition that the pulling direction of clamped end of zipper band was precisely vertical to a horizontal X-stage under a specified feed velocity. Since a real tearing-off of zipper band is done by a human hand, the pulling direction of clamped end of zipper band seems to be generally inclined (left-right asymmetry) or twisted against the cutting lines, and also its pulling velocity seems to be higher or lower than that of this working. Such conditions of hand tearing should be discussed furthermore from aspects of human sense or ergonomics. As this working is limited in the specified condition, to collect all tearing data regularized by the specified method is possible and convenient to compare the performance of zipper tearing test with collected database.

\section{Acknowledgement}

This work was supported by a fund for developing a core of excellence as innovation and branding project from the GIGAKU Innovation promotion center, NUT, 2012-2016. The authors wish to thank Haruya Kambe, who was an undergraduate student of NUT, for his contribution in 2016.

\section{Nomenclature}

$b$ : width of zipper band (pull tab), $b=3,10,30$ (mm)

$b_{\mathrm{R}}, b_{\mathrm{L}}$ : width of right side panel and left side panel to the direction of tearing of pull tab

$a_{\mathrm{n}}$ : length of a connecting portion (uncut zone) along the cutting line

$\phi$ : attitude angle of cutting line against the grain direction of paper making, $\phi=0,90\left(^{\circ}\right)$

$\theta_{a}$ : pulling direction of band end against flap panels, $\theta_{a}=60,90,120\left(^{\circ}\right)$

$F$ : tearing tensile force of clamped band end

$x$ : displacement of clamped band end in the vertical direction

$F_{\mathrm{pi}}$ : the peak maximum tearing force at the i-th stage (the i-th connecting portion), (i=1, 2, 3 was considered)

$F_{\mathrm{p} 1,60}, F_{\mathrm{p} 1,90}$, and $F_{\mathrm{p} 1,120}$ : the first peak force at the specified pulling direction $\theta_{a}=60,90$ and $120\left(^{\circ}\right)$.

$p$ : success rate (probability) of connecting portions by pulling clamped end of zipper band 


\section{References}

All packaging company, Folding Carton Structures Defined, online available from <http://www.allpack.com/Structures Defined.php> (accessed on November, 2016).

Bronkhorst, C. A. and Bennet, K. A., Tear Strength in Chapter 7 Deformation and Failure behavior of Paper, Handbook of Physical Testing of Paper, Vol.1, (1983), pp.388-395.

Kirwan, J. M., Handbook of Paper and Paperboard Packaging Technology 2nd ed., (2013), pp.268-287, Wiley-Blackwell. Lyne, M.B., Jackson, M.A. and Ranger, A.E., The in-plane, Elmendorf, and edge tear strength properties of mixed furnish papers, TAPPI, Vol.55 No.6, (1972), pp.924-932.

Nagasawa, S., Taga, T., Fukuzawa, Y., Murayama, M. and Katayama, I., Effect of Cutting Line End of Paperboard on Pushing Load Characteristics of Center Bevel Blade, Journal of the Japan Society for Technology of Plasticity, Vol.48 No.560, (2007), pp.829-833 (in Japanese).

Nagasawa, S., Abdul Hamid, D., Kikuchi, K., Fukuzawa, Y. and Katayama, I., Tensile Characteristics of Connecting Portions of Paperboard Subjected to Indentation of Nicked Center Bevel Blade, Journal of the Japan Society for Technology of Plasticity, Vol.49 No.564, (2008), pp.66-70.

Nagasawa, S., Chaijit, S., Takahashi, T., Fukuzawa, Y., Kikuchi, K. and Hine, A. Effect of Rubber Fixture on Cutting Characteristic of White-coated Paperboard, Journal of the Japan Society for Technology of Plasticity, Vol.50 No.576, (2009), pp.29-33 (in Japanese).

Nagasawa, S., Yamashita, Y., Abdul Hamid, D., Fukuzawa, Y. and Hine, A., Out-of-Plane Shearing Characteristics of Coated Paperboard, International Journal of Mechanical Sciences, Vol.52 No.9, (2010), pp.1101-1106.

Nagasawa, S., Uehara, M., Matsumoto C., Kambe, H., Jina, W., Estimation of Stress and Displacement around Nick Zone of Zipper Pull Tab Formed on Paperboard, Proc. of the 2017 Int. Conf. on Materials \& Processing, (2017), Paper No. ICMP2017-4303, pp.1-7.

Nagasawa, S., Uehara, M., Matsumoto, C., Effects of Guiding Routes and Grain Direction of White-clay-coated Paperboard on Tearing Characteristics of Zipper Pull Tab, Journal of the Japan Society for Technology of Plasticity, Vol.59 No.685, (2018), pp.15-20 (in Japanese).

Reinhard, S., Werner, A., Werner, K., and Martin, T., Chapter 17 Surface Sizing and Coating, Handbook of paper and board (ed., Holik, H.), Vol.2, (2013), pp.747-772, WILEY-VCH Verlag and KGaA, Weinheim.

Yamauchi, T., Tanaka, A., Tearing test for paper using a tensile tester, Journal of Wood Science, Vol.48, (2002), pp.532535. 